\title{
Mutuality: A root principle for marketing ethics
}

\section{Author:}

Juan Manuel Elegido'

Affiliation:

1 Pan-Atlantic University, Lagos, Nigeria

\section{Correspondence to:}

Prof. Juan Manuel Elegido Lagos Business School Pan-Atlantic University P.O. Box 73688

Victoria Island, Lagos Nigeria

E-mail:

jelegido@pau.edu.ng

DOI:

10.15249/10-1-128

\section{Keywords:}

marketing ethics; responsibilities to customers; consumer sovereignty; paternalism, perfect competition; mutuality; equality

\section{Abstract}

This paper seeks to identify a mid-level unifying ethical principle that may help clarify and articulate the responsibilities of business firms in the field of marketing ethics. The paper examines critically the main principles which have been proposed to date in the literature - namely consumer sovereignty, preserving the conditions of an acceptable exchange, paternalism, and the perfect competition ideal and concludes that all of them are vulnerable to damaging criticisms.

The paper articulates and defends the mutuality principle as the most plausible candidate for the role of master principle in the relations between a firm and its customers. This principle requires that sellers look for reciprocity in their relations with their customers, seeking to provide to their customers something that helps them improve in some way their wellbeing and is commensurate with what they (the sellers) receive in return.

The paper also compares the mutuality principle with other ethical principles relevant to the field of marketing ethics.

\section{Introduction}

Many issues of ethical significance arise in the interaction between a firm and its customers. To refer to only a few: in relation to pricing, decisions may have to be made about whether to take advantage of lack of competition or a surge in demand by increasing prices well above costs, or engage in price discrimination; in relation to product design, issues arise such as how far to go in spending resources in an effort to increase quality or make products safer; in choosing target 
markets, problematic issues include how far to go in serving lower income segments that may benefit greatly from the firm's products, but are relatively less attractive than more affluent groups, and whether to target certain more vulnerable market segments; in promoting the firm's products, issues may arise as to whether certain advertisements are acceptable.

A rich literature has appeared, mostly during the last thirty-five years, addressing ethical issues in marketing. Review articles of work done in the field of marketing ethics by Gaski (1999), Nill and Schibrowsky (2007), and Schlegelmilch and Oberseder (2010), refer to over two hundred articles. It is fair to qualify this impressive result by pointing out, as the second review just cited does, that most of the work done relates to empirical questions, while normative issues have received substantially less attention. Still, as a cursory look at the works cited in this article will show, there has also been significant work on substantive ethical questions in the field of marketing.

When addressing problematic ethical issues in marketing, it is possible to try to go back to ultimate ethical principles. In fact some prominent ethicists have done so, sometimes with conspicuous success. It may be enough to refer to Tom Carson's treatment of personal selling (2001) and to Germain Grisez' discussion of several issues of business ethics (Grisez, 1997). The main problem with such an approach is that it is very difficult to do it well, as there are many points - both of philosophical theory and business practice - at which it is possible to take a wrong turn while trying to determine the bearing of an ultimate principle such as the Golden Rule or the eudaimonic principle on a specific business issue (Strutton, Hamilton \& Lumpkin, 1997:545-546; Whysall, 2000:189). Matters are still more difficult when several ultimate principles are relevant. And the problem is even more acute for business people, who usually lack specialized training in moral philosophy (Smith, 1995:87).

Perhaps because of this difficulty, both business ethicists and (even more frequently) thoughtful practitioners often try to take a shortcut and address each issue as it arises on the basis of their intuitions on the ethical merits of the case. Some examples, among many, of this approach in the business ethics literature are Bhandari (1997), on the computation and disclosure of the cost of credit; Brenkert (1998), on marketing to vulnerable groups; and Ebejer and Morden (1988), on limited paternalism. However, this approach is inherently exposed to dangers of bias, inconsistency and arbitrariness. There is also empirical evidence that our moral intuitions may be unstable, in the sense that they vary significantly depending on the level of detail with which a situation is described (Freiman \& Nichols, 2011). An even more radical problem with intuitionist approaches is that often different people have conflicting intuitions on what should be done in a given situation. In such cases there would seem to be no rational method to resolve differences in moral judgment within the limits of an intuitionist approach to moral decision making.

An alternative approach is to search for a unifying mid-level ethical principle that may help clarify and articulate the ethical responsibilities of business firms towards their customers. This has been done in other areas of business ethics (Enderle \& Niu, 2012; Primaux \& Stieber, 1999). 
What is the meaning of the term 'mid-level ethical principle' in this article? Mid-level principles may best be understood by comparing them to 'ultimate ethical principles' and 'more specific action-guiding principles'.

Different schools of thought in ethics have different views as to the fundamental ethical principle. Kant, for instance, takes as the ultimate ethical principle the categorical imperative; for Aristotle, it is the eudaimonic principle; for Bentham, the principle of utility, or maximization of pleasure over pain. Whichever principle(s) a person accepts as fundamental will be taken to apply to all domains of human activity. Thus, for instance, a utilitarian will use the principle of utility to ascertain moral norms in fields as different as business, sexual activity, tax policy, communication and politics.

Someone who accepts one or more of these ultimate ethical principles will use them to justify concrete moral norms or principles capable of guiding their behaviour in specific circumstances. For instance, if a utilitarian believes that the practice of price discrimination maximizes total utility, he will conclude that price discrimination is permissible (or even required). Thus, while the principle of utility is an ultimate ethical principle, "it is permissible (or even required) to engage in price discrimination" would be what I called above a 'more specific action-guiding principle'.

I consider a principle to be a 'mid-level principle' if it has three characteristics: (i) it derives its force from ultimate ethical principles; (ii) it has a wide domain of application, so that it is applicable to all (or most of) the moral issues that arise in a given field of activity (e.g. marketing); and (iii) it unifies the more specific moral norms applicable in that domain, in the sense that it can be used to justify all (or most) of them. Thus, for instance, I consider the fiduciary principle to be a mid-level ethical principle in the field of corporate governance.

Within the field of marketing ethics, the main unifying mid-level principles which have been proposed in the literature over the past thirty years include consumer sovereignty (Smith, 1995); preserving the conditions of an acceptable exchange (Holley, 1986); paternalism (Brock, 1996; Kultgen, 1995; Penz, 1986); and the perfect competition ideal (Velasquez, 2006; Wertheimer, 1996). A potential problem with the approach of using mid-level principles is that there is need to be very careful in articulating them, so as not to be seduced into accepting what may ultimately prove to be an unsound principle by its apparent initial plausibility.

On the other hand, this method has two important advantages. First, as is exemplified in the field of human rights, there is often agreement on the validity of a mid-level ethical principle among people of different philosophical persuasions, each of whom justifies the principle in a different way. Secondly, the identification of such principles makes it much easier for enlightened practitioners to reason ethically (Smith, 1995:87; Whysall, 2000:189). It often proves impossible in practice for a practitioner to try to reason her way from ultimate principles to a reliable conclusion in any moderately complex ethical issue she meets for the first time, as principles are open to different interpretations and therefore leave too much room for rationalisation. In my experience, my own students seem to find it much easier to 'think ethically' whenever I have been able to provide them 
with mid-level ethical principles. Of course, the key question is whether any proposed mid-level principle for a given domain of activity (such as the field of marketing) is actually sound. In order to make progress on this there is need for business ethicists to focus on the discussion of such principles, as I propose to do in this paper.

This paper criticises the main alternative mid-level ethical principles that have been suggested for the field of marketing and argues that the principle of mutuality is superior to them. This principle suggests that in their dealings with buyers, sellers should seek to establish a cooperative relationship based on reciprocity, in which both parties can benefit from their interaction. This cooperative relationship is distinguished from others based either in pure beneficence (which focuses on the interests of the other party, to the point of forgetting those of the seller) or in egoism (which makes of the buyer a mere means to the advancement of the seller's interests).

\section{Some suggested mid-level principles for marketing ethics}

In seeking to identify a sound basic standard for marketing ethics it will be useful to start by examining critically the mid-level principles that have already been proposed by different authors and, in so far as the principles examined may prove vulnerable to telling objections, proceed to the positive task of trying to articulate a more satisfactory principle. ${ }^{1}$

\section{Consumer sovereignty and preserving the conditions of an acceptable exchange}

These are two different principles, which have been proposed independently by two different ethicists and are justified on the basis of different premises. However, they are very similar in their practical implications for marketers. Since my criticisms of these two principles focus on the consequences of applying the normative conclusions that flow from them, it will save space to consider them together. As will be seen, my main criticisms of these two principles are that they assume an implausible desire-fulfilment theory of well-being and that they unduly conflate the roles of seller and buyer's agent (and force the buyer to pay for both of them).

N Craig Smith (1995) has proposed the principle of consumer sovereignty as a standard to ethically evaluate marketing decisions. According to this principle, marketers must ensure that in their interactions with consumers, the latter should enjoy capability, information and choice. As explained by Smith, capability is denied by vulnerability and requires that the consumer be able to make effective decisions in relation to a given product. Information requires that consumers have sufficient knowledge to understand the risks of a given product and judge whether their expectations at the time of purchase are likely to be fulfilled. Consumers have choice if they have alternatives and are actually able to go elsewhere if they are not satisfied with a given seller's offer.

The principle of preserving the conditions of an acceptable exchange was proposed by Holley (1986). He argues that "[p]eople in business who support the market system and 
benefit from it have a responsibility for minimizing abuses which undermine the system's moral legitimacy” (Holley, 1986:18). Accordingly, Holley bases his ethical evaluation of sales practices on the idea that "the primary duty of salespeople to customers is not to undermine the conditions of acceptable exchange" (p. 5). He considers that an acceptable exchange is one that is "adequately informed, rational and free from compulsion" (ibid). Holley recognises that these conditions are subject to degrees of fulfilment, as " $[\mathrm{k}]$ nowledge can be more or less adequate. Individuals can be subject to various irrational influences. There can be borderline cases of external constraints" (ibid). Still, he asserts that "[e]ven when conditions are not ideal, we may still have an acceptable exchange" (ibid; Holley's italics). It is easy to appreciate that what this principle demands of sellers is very similar to the requirements of the principle of consumer sovereignty.

Much can be said in favour of these two principles from the point of view of the consumer. In a certain way they approximate the principle of mutuality, for which I will argue below, as, if one grants that consumers are the best judges of their own interests (admittedly, a heroic assumption if it is presented as something that is always the case), then in so far as consumers have capability, information and choice (in the words of Smith), or information, rationality and freedom from compulsion (in the broadly similar formulation of Holley), they themselves will be able to ensure that they get appropriate value in all transactions in which they engage. Still, there are problems. The first arises from the widely documented inability of consumers to make informed decisions on many occasions (Sirgy \& Su, 2000:2-4 and 7-9; Sirgy, Lee \& Grace, 2011:462-465). There is an enormous literature showing the systematic irrationality of many decision processes and therefore of the preferences to which they lead, as decision making is often affected by distorted perceptions, skewed memory of past events, errors in assigning probabilities to uncertain events, the way in which data is presented, inappropriate taking into account of sunk costs, and failure to take into account judgmental limitations (for good summaries of this literature, see Hardman, 2009; Hogarth, 1987; and Zamir, 1997).

Even more fundamentally, at the root of this issue lie basic assumptions that have been discussed in the contemporary literature by way of considering alternative theories of well-being. Most of these theories can be grouped into three main types: hedonistic theories, desire-fulfilment theories, and objective list theories (Arneson, 1999:4; Crisp, 2013: Section 4; Parfit, 1984:493-501). Broadly speaking, hedonistic theories identify well-being with pleasure; desire-fulfilment theories propose that well-being is a matter of achieving what we desire; and objective list theories consider that well-being is achieved by obtaining one or more good things or attaining certain conditions that make people better off.

There is near unanimity among philosophers of very different persuasions that the desirefulfilment theory is vulnerable to fatal objections. One is that saying that well-being is identical with satisfying our desires is equivalent to saying that human beings (or at least sane adults of ordinary intelligence) never act in ways contrary to their interests. But of course, we all do, at least from time to time. Just think of desires that derive from erroneous information or psychological problems (e.g. addiction) in the subject and whose satisfaction is bound to result in impairment to that subject (Arneson, 1999:18-19; 
Brandt, 1979:38; Broome, 1999; Griffin, 1986; Lewinsohn-Zamir, 2003:1678-1679; Scanlon, 1975:186). The phenomenon of learned overly modest preferences is also very significant and provides a strong argument against desire-fulfilment theories of well-being. Members of a subjugated group may adjust themselves to their subservient role and eventually feel satisfied with the modest achievement allowed them; they may set low goals for themselves and actually achieve them, and in doing so may at least succeed in reducing their feelings of frustration and generally reduce cognitive dissonance, but obviously this does not make for a good life (Anderson, 1995:30; Sen, 1985:191).

This is a very wide issue and it is impossible to address it adequately as a subsidiary matter within the limits of this paper. Suffice to say that if the desire-fulfilment theory is rejected, the attractiveness from the point of view of the consumer of the two principles we are examining here is severely undermined, and that currently this theory has few adherents among philosophers.

The principles of consumer sovereignty and preserving the conditions of an acceptable exchange suffer from even greater shortcomings when they are assessed from the point of view of the seller. Demanding that the seller ensure that her consumers enjoy capability, information and choice (or information, rationality and freedom from compulsion) in all transactions is a very exacting standard. Thus, for instance, consistent with the basic idea that the seller must provide information to consumers so that they may be in a position to effectively satisfy their preferences, Smith defends the idea that a salesman "has a duty to disclose information that could influence a consumer's purchase decision, such as an impending new model of the product" (Smith, 1995:92²). However, it is not selfevident that in a transaction between competent adults it should be the responsibility of the seller to provide the buyer with all the information that the latter might consider relevant. A seller may well undertake to provide a certain product without further undertaking to be a consultant for her buyers - far less an agent, with the consequent fiduciary responsibilities. Of course, on some occasions a seller may accept to play all these roles and presumably she will require to be compensated accordingly, but there seems to be no reason of principle why a seller should always be obliged to perform all these functions, and even less reason why all buyers should be obliged to pay for them, even when they would prefer to receive a more limited service from the seller and pay a cheaper price for it. In this respect, at least, the ideal of consumer sovereignty, as expounded by Smith, seems to be incoherent, for by insisting on the bundling of different products and services (the product or service on sale and the services of consultant and agent), it seems to deprive buyers of an important aspect of their sovereignty: the freedom to decide which services they want (and are ready to pay for) from the seller and which services they do not want (and prefer not to have to pay for). Also, as Carson (2001:283-284) has pointed out (addressing his comments to Holley), sellers may just not have enough time to provide the information required by these principles; or it may be the case that they (or the mass of their employees) simply lack the information themselves and it would be unreasonable to require them to make the investment of time and effort that might have to be made in order to obtain it. Carson also points out that the seller may just not know enough about the buyer to be able to estimate the information the 
latter would need in order to be able to decide if the purchase would be beneficial to her in her own circumstances.

It is also far from clear that sellers have the responsibility to ensure that their buyers should have effective freedom of choice. As Carson (2001:285) has pointed out, criticising Holley, holding that they have this responsibility yields unacceptable consequences in situations in which the buyer's alternatives are severely constrained. Carson gives the example of somebody of modest means trying to buy a house in a small town. If there is only one house that the buyer can afford, her freedom of choice would be severely constrained. How could it be the responsibility of the seller to ensure that there is freedom of choice in such circumstances?

\section{Paternalism}

The paternalistic principle has been put forward in various forms to orientate the relations between firms and their customers. In this section I will criticise paternalism on the basis of the importance of giving all due weight to the idea that self-determination is a great human good that is eroded by paternalism. I will also argue that the proper role of a seller is that of a servant who places his specialised knowledge at the service of the buyer and allows her to retain the ability to control the relationship in the light of her own values and preferences.

For the purposes of this paper, and consistent with the approach of several prominent philosophers who have studied this issue (e.g. Arneson, 2005; Dworkin 1988 and 2010; and Feinberg, 1986), I will take a conception of the responsibilities of marketers to be paternalistic if, according to it, a business firm has the responsibility of ensuring that, as much as possible, its clients do what in the view of the firm will advance their well-being, even if, were they free to do so, they would be likely, or certain, to prefer to do something different.

This way of acting is paternalistic in the sense that it advocates a model of conduct similar to that which is often adopted by parents with respect to their young children. Responsible parents, for their children's own good, can rightly decide to intervene in the life of their minor children, without giving them the opportunity to choose those alternatives the parents consider harmful. Those who advocate paternalistic principles feel that we often have a responsibility towards other people that is similar to that which parents have towards their minor children; that is, a responsibility to protect and advance the children's interests, regardless of, or even against, their own preferences. This conception of the responsibilities of marketers has, at least in its broad outlines, been defended by authors like Penz (1986), Kultgen (1995) and Brock (1996).

Kultgen offers both a long definition of paternalism (he calls it 'parentalism') and a shorter one. A reference to the short one will be enough for my purposes here. Kultgen characterizes an action as paternalistic (or 'parentalistic') "if it is an intervention in a subject's life for his benefit without regard to his consent” (Kultgen, 1995:62). This definition substantially coincides with the conception of paternalism I sketched above. 
My conception of paternalism can be usefully contrasted with that of Ebejer and Morden (1988). They defend a thesis that they call 'limited paternalism', which, upon inspection, differs substantially, and not only in degree, from the conception of paternalism I have put forward and will be using here. Ebejer and Morden (1988:338) argue that marketers have a duty

to inform customers fully about a product or service, to disclose fully all relevant information without hiding crucial stipulations in small print, to ascertain that they are aware of their needs and the degree to which the product or service will satisfy them $[\ldots]$.

On my definition this is not paternalism at all, since the crucial element of trying to substitute one's own judgement for that of the customer, for the latter's own good, is missing. By providing information to another, or by not misleading him, I neither deprive him of autonomy nor undermine his ability to self-govern in any way.

Examples of a paternalistic outlook are common in the practice of many professions. In the field of medical ethics, the Hippocratic tradition, with its view of the physician as a benevolent and wise caregiver who knows what is best for her patients and makes decisions for their benefit but without their participation, was dominant in most countries until around forty years ago (Pellegrino \& Thomasma, 1993). Up to this day, other professionals often minimize the scope of choice they offer to their clients and try to steer them towards solutions they consider sound.

It is in principle possible to offer a variety of justifications for paternalism, but the sustained defences of this principle which I have come across, both within the field of business ethics and in the area of political philosophy, are consequentialist in character. Thus, for instance, Kultgen (1995:76) states that "[p]ersons are justified in acting [paternalistically] if and only if they believe that the expected value of the action for the recipient is greater than any alternative and they have reason to trust their own judgment despite the opposition of anyone, including the recipient". Brock's position is more complex, and she values the autonomy of the beneficiary more highly than Kultgen does, but ultimately the justification she offers is also consequentialist:

Respecting someone's autonomy is a prima facie good. So is furthering someone's well-being. The issue is what to do when opportunities arise which require a choice between the two prima facie goods. One must weigh up which is to enjoy precedence in such cases.

(Brock, 1996:541-542)

In broader contexts, the justifications of at least some degree of paternalism offered by Mill (1956), Arneson (2005) and Dworkin (1988) are also consequentialist in character.

However, even in consequentialist terms, the case for paternalism in the firm-customer relationship is very weak. (A somewhat stronger case can be made for paternalism in other contexts). In the first place, it is well to remember that there is great potential for self-deception when acting paternalistically. People who believe that they are trying to serve the interests of others while bypassing their capacity to choose, often are neither perfectly disinterested nor fully aware of their own prejudices and inclinations. In 
business contexts, in which there is frequently a tension between the interests of firm and customer, there are many opportunities for self-deception and for fostering one's own interests while believing oneself to be serving the interests of others.

Secondly, would-be paternalists often suffer from a significant deficit of knowledge, which greatly handicaps their efforts to do what is good for another, especially when the very strategy they pursue often prevents them from frankly asking their customers about their preferences. Each of us is differently circumstanced in relation to our own financial position and prospects, the portfolio of alternative possibilities and opportunities open to us, what we are trying to achieve in a given circumstance, and our overall long-term aims. Specific choices often only make sense against a background of circumstances, values, preferences and priorities, a given lifestyle and, even more fundamentally, a given life plan. This point has greater practical importance in view of the fact that most of us live in highly pluralistic societies in which people adhere to a wide variety of moral views and in which seller and buyer may have markedly different preferences and values. It is very possible, for instance, that something that could indeed be a great benefit for a person of certain values and purposes may not be a benefit at all, or could even be positively harmful, for somebody with different values and purposes. At the very least, the relative value of a given benefit, and therefore what one would be willing to give up in order to secure it, could vary greatly depending on one's circumstances and preferences. As each of us is in a privileged position to know our own specific circumstances in all these respects, it follows that we are much more likely to be able to assess what is beneficial for us here and now than a stranger, no matter how well meaning (and in the realm of commercial transactions we usually deal with strangers).

Thirdly, it is very important to keep in mind that self-determination is itself a great good, and that somebody's opportunity, or lack of it, to exercise control over her own life has to be weighed in making a consequentialist assessment of a policy of paternalism. That a person is the author of her own life, that she has the opportunity to shape her character and career through her own decisions, has great significance in itself, beyond the results that may flow from each concrete decision. When others take a decision on my behalf and without consulting me, even if in fact they act 'for my own good', they deprive me of an essential part of 'my own good': the opportunity to develop my capacity for making responsible decisions, and ultimately, of truly being the author of my own life. In this sense, they deprive me of an essential means for self-fulfilment.

Beyond all the preceding considerations, however, we cannot limit ourselves, in making a moral assessment, to weighing the consequences of the various courses of action open to us. There are many reasons for this - and this is a topic that has been canvassed extensively over the past thirty years - but the most fundamental ones are that it is impossible to commensurate rationally, in the way required for an overall moral assessment, the different consequences of any given action (Finnis, 1980:112-116; Grisez, 1978:37-41); and that the respect due to persons demands that their right to be the architects of their own lives, according to their freely chosen values and commitments, be recognised. As Isaiah Berlin eloquently put it: 
I wish to be a subject, not an object ... deciding, not being decided for, self-directed and not acted upon by external nature or by other men as if I were a thing, or an animal, or a slave incapable of playing a human role, that is, of conceiving goals and policies of my own and realizing them.

(Berlin, 1969:131, cited in Dworkin, 1988:13)

The capacity human beings have to responsibly choose and implement a life plan and make responsible judgments in living their own lives is an essential aspect of what it means to be human, and to undermine or try to circumvent that capacity constitutes a denial of respect, in so far as it constitutes a violation of their integrity and a removal of their responsibility for their lives. While we have a responsibility to help others to live their lives, attempting to take over their lives and make decisions for them in situations in which they are not actually deprived of their ability to make these decisions and harm to third parties is not in question, is incompatible with the respect due to them as rational agents.

It follows from all this that a firm is not justified in seeking to advance its customers' well-being when doing so requires acting in opposition to these customers' own values and preferences and actively depriving them of the capacity to make their own choices; and that in the relationship firm-customer, the role of the firm is that of a servant who places her superior knowledge at the service of the customer while refraining from forcing on him its own values and preferences, while it is for the customer to set the objectives of what is to be accomplished and to retain overall control of the relationship so as to retain the ability to shape his own life.

It is important to understand with precision the implications of the above discussion. From a denial of the soundness of a paternalist principle it follows that a business person is not justified in trying to force on the customer or client, 'for her own good', courses of action which are contrary to the client or customer's own preferences, or in trying to manipulate the information offered to her so as to ensure that she makes the 'right choice'. However, this is not to say that the business person has a responsibility to actively help his customers carry out their choices, no matter how self-destructive these may be (and we have seen above that they may indeed be self-destructive; that they are not guaranteed to advance the customer's well-being by mere virtue of the fact that they are her choices). This assertion of the right of the business person to not cooperate in the misguided choices of some clients is not grounded on a paternalistic foundation, but rather on the fact that the business person also has his own life to live, and has the right not to undermine it because others insist on following a self-destructive course of action (Pellegrino \& Thomasma, 1993:96-97, 130).

\section{The perfect competition ideal}

One often gets the impression in discussions of business ethics and economics that their authors seem to believe that if the conditions of an exchange are such that what customers get is worse than what they would get under conditions of perfect competition, that is, insofar as it happens, an indication that the seller is not behaving fully ethically. In other words, it is assumed that the standards of perfect competition are themselves 
ethical standards. This is most often an unexamined assumption, but sometimes this position is articulated reflectively. A clear example of this way of thinking is provided by Wertheimer's discussion of justice in pricing. Wertheimer (1996:230-236) argues that, at least for a range of cases, a hypothetical market price - the price that would be generated by a competitive market - provides the standard for a fair transaction. Wertheimer does not work out in detail what he has in mind, but from the statements he makes and the examples he offers, it seems justified to conclude that his position is that when a seller is not constrained in fixing a price for his product by the actual existence of a competitive market, he should try to estimate the price at which the product would sell on the hypothesis that such a competitive market existed. That would be the fair price at which to sell that product.

Another example of this approach is provided by Velasquez (2006). He organises his discussion of ethics in the marketplace around the models of perfect competition, monopoly and oligopoly. Once he has made this crucial move, the reader will not be surprised when she learns that, for Velasquez, perfect competition is ethically superior to the other two possibilities. In his view, perfectly competitive free markets achieve three major moral values: they distribute benefits between sellers and buyers according to their contribution (see pp. 91 and 172-73); they maximise the utility of buyers and sellers by allocating resources in a way that produces the highest level of satisfaction possible from those resources (pp. 173-74); and they respect buyers' rights, as all exchanges are fully voluntary (p. 174). By comparison, a buyer who faces a monopolistic or an oligopolistic seller will not fare nearly so well. Velasquez, for instance, states that "the high prices the [monopolistic] seller forces the buyer to pay are unjust" (p. 180), and that "oligopoly markets, like monopolies, can fail to exhibit just profit levels" (p. 182).

But, of course, there are significant problems in moving from the advantages that the buyer would reap in a world of perfect competition to a prescription that actual sellers, in a world that by and large is far removed from that ideal, should approximate their actions to the way that they are presumed to act within that model.

In the first place, while a perfectly competitive market has clear advantages for buyers, it also has shortcomings which, on balance, make it not so desirable in many circumstances, especially in situations where there is room for innovation and product differentiation. There are many industries nowadays in which substantial fixed or sunk costs (especially from research and development) and very low marginal costs are the norm. Examples of such industries are pharmaceuticals and software development. If firms in such industries had to behave like sellers operating in a perfect competition market, they would be unable to recoup their research and development costs in many cases. This would mean that they would not engage in such research and development, and therefore there would be no new products, or at least no significant new products.

The requirement that sellers should behave in the way that they would in a perfectly competitive market is often also unfair. Sellers are asked to act as they would do if everybody (not only other sellers, but everybody else, including their suppliers, employees, investors and customers) were acting in ways that perfectly tracked the 
perfect competition model. But, as the perfect competition model is a model and not a description of the real world, in fact almost nobody else acts in that way. In an ideal world there would be universal peace and no country would need to have an army, a police department or a criminal justice system. This does not mean that it is a duty of justice for all states in the world to dismantle the institutions they have created to cope with the problems that arise in the less-than-ideal world in which we live.

\section{The mutuality principle}

My discussion of the four main mid-level principles that have been put forward to regulate the relations between buyers and sellers has unearthed some significant problems with these principles. The principles of consumer sovereignty and preserving the conditions of an acceptable exchange assume a flawed desire-fulfilment theory of well-being and make excessive demands on sellers. The paternalistic principle fails to accord due weight to the great value of self-determination. Finally, the perfect competition ideal seems to assume that we live in an ideal world in which the stringent demands of the perfect competition model are met.

I will now describe an alternative mid-level principle which I consider to have significant advantages over those already discussed, namely the mutuality principle.

The mutuality principle (MP) requires that sellers avoid seeking unilateral advantage in their dealings with buyers and that they aim instead to establish a relation of reciprocity. In accordance with this principle, the main responsibility of a seller towards his buyers is that of providing them with goods and services that are effectively capable of contributing to their well-being within the framework of a mutually beneficial exchange. While this principle demands that buyers should not be viewed merely as means to make a profit, it does not demand that the seller neglect his own interests. Moreover, it does not assume that the customer is helpless, nor that the responsibility of serving the customer is the only one the seller has or that it takes priority over all others. In consequence, it does not require that the seller provide the best possible deal to the buyer. I will now proceed to expand on this quick outline and endeavour to justify MP.

The mutuality principle is an ethical principle that reflects a concern with the wellbeing of others. It avoids the purely selfish policy of being ready to take advantage of the ignorance, special need or carelessness of the other party to lead him towards a transaction that is not in his own interest. As its name indicates, MP requires that a seller should instead seek to establish real reciprocity between what he provides to his customers and what he receives from them. As part of this endeavour to seek reciprocity, MP demands from the seller an active effort to do his best to ensure that his product is really useful to the buyer. One could translate this into contemporary jargon by saying that a seller guided by MP should look for his own profit (as we will see below, this is in no way excluded by MP) through win-win transactions. An exchange in which I win precisely by inducing you to do something that I know undermines your interest is radically incompatible with an active concern for your well-being. 
Most fundamentally, MP is based on the idea of seeking that the transaction between buyer and seller be a cooperative undertaking for their mutual benefit. The idea is that the seller makes a profit as just reward for providing value to the buyer. Accordingly, the first requirement of this principle is that the seller make a reasonable effort to advance the interests of the buyer by providing to him something that is of value to him (Elegido, 1998:92-93 and 98-100; Melé, 2009b:276-279). It is therefore essential to this principle that the seller render a service to the buyer (Elegido, 1998:98-99; Guitián, 2015:66-70; Melé, 2009b:277-278).

As I will discuss below, there are important limitations of principle (such as respecting the autonomy of the buyer) and of a practical type (such as the ability of the seller to know accurately the circumstances and interests of the buyer) which place stringent limits on the ability of the seller to attain this ideal and actually provide a real service. It is obvious, however, that sellers will not be trying to provide a real service to their buyers if the very products they sell are ineffective or harmful, or if they systematically try to encourage their buyers to buy the product that is most immediately profitable, irrespective of the buyers' interests (Gibbs, 2004:9-10). Generally speaking, it would be incompatible with this active concern to provide buyers with something that will leave them better off for sellers to take advantage of buyers' weaknesses by selling them products or services that would neither contribute to solving any of their problems nor enhance their well-being, or that would do so less effectively than alternative products that the sellers also have available, or, even worse, by selling products that will be harmful to buyers. Examples of possible weaknesses of buyers that could make it possible for sellers to profit at the expense of the buyers are ignorance or inexperience; physical or psychological addictions (e.g. those that may afflict smokers or gamblers); situations of emotional weakness (e.g. the well-known example of the widow who is arranging for the burial of her recently deceased husband); special need (e.g. the patient who needs an urgent surgical operation); and monopoly (Baker, Gentry \& Rittenburg, 2005; Smith \& Cooper-Martin, 1997).

However, MP does not exclude a concern to advance the sellers' own interests in an all-out effort to give the best possible deal to their buyers. What mutuality demands may be stated negatively as requiring that one party does not gain precisely through the other's loss. It may also be formulated positively as requiring that, in so far as it is practically possible, sellers endeavour to make both their buyers and themselves better off through their activities. Therefore, there is nothing in this principle that precludes sellers from making large profits; all it requires is that they make their profits by creating very high value for their buyers and then insisting on receiving commensurate benefits from those buyers. If they succeed in doing this while keeping their costs low, it will be possible, in strict conformity with this principle, for such sellers to contribute a lot of value to others and to do very well for themselves and for those to whom they bear special responsibilities. It is also worth stressing that this principle does not require the seller to provide as much value as possible, or any given value at the cheapest possible price which can be sustained without pushing the seller into loss. For so long as the seller provides commensurate value in return for the money he receives from his buyers, the requirements of this principle will have been satisfied. Perhaps the simplest and 
most popular way to express this requirement is to say that sellers should provide 'value for money'.

It will be useful at this stage to identify some of the concrete requirements of MP. At this point I will limit myself to enumerating these requirements; their rationale will be better appreciated as we discuss the principle further in the rest of this article.

- In designing its products, a firm acting in accordance with the requirements of MP will endeavour to make them safe and functional, so that they may be capable of performing effectively and safely the tasks for which they are likely to be acquired. However, that firm will not feel obliged to attain the highest possible quality and safety, or to provide the best possible after-sales service.

- When making pricing decisions, such a firm will not just try to get as much as it possibly can, taking advantage of every opportunity to do so, but will endeavour to get a price commensurate with the value it provides to the customer (though not necessarily the lowest possible price, or even a price that is affordable to all or most customers) (Elegido, 2009 and 2015; Sirgy, 1996:250-251).

- The communication, promotional and selling activities of such a firm will not attempt to subvert the autonomy of its customers, and will be geared to preventing them from forming beliefs or expectations that may make it more difficult for them to act in such a way that a mutually beneficial outcome is reached (Holley, 1986:16; Sirgy, 1996:253). In addition, such activities will also refrain from inducing customers to consume products in a harmful way (Melé, 2009a:278). Thus, for instance, a wine marketing company will not try to encourage its customers to drink as much as possible or to drink in inappropriate situations. However, mutuality does not require that the firm provide buyers with all the information which it would be to their benefit to have, because it does not demand that the firm becomes the customer's agent.

- Finally, MP also demands that the seller refrain from undermining in other ways the interests of the buyers, as for instance by eroding their autonomy or privacy (Laczniak \& Murphy, 2006b), or, in an effort to increase their sales, by promoting through their messages materialistic values which may lead to lower self-esteem (Chaplin \& Roedder, 2007) and increased risk of anxiety and depression (Schor, 2004).

After this brief introduction of MP it is already possible to appreciate how it differs in important respects from each of the alternative mid-level principles discussed above.

\section{Justification of mutuality}

What can be said specifically in favour of following MP in business dealings? I will structure the justification of this mid-level principle in two stages. First, I will try to answer the question Why mutuality? That is to say, I will try to justify why a seller should concern himself with the interests of the buyer, even if this may not contribute to maximising his own benefit. After all, even with the qualifications I introduced before, the demands of MP may seem too strict to many business people. A writer as knowledgeable in the field of marketing ethics as David Holley has summarised his 
view of the standards commonly accepted on this issue by remarking that "it is usually expected that the activity of sales will involve a primary pursuit of the interests of the seller" (Holley, 1998:631). However, MP contends that it is ethically required to go beyond the pursuit of self-interest in market transactions.

As a second stage in the argument I will try to answer the question Why stop at mutuality? Some people may wonder whether it would not be more ethical to progress beyond mutuality to a more demanding effort to satisfy more fully the needs of the customer, and these concerns deserve attention.

\section{Why mutuality?}

The idea of mutuality has a certain intuitive attraction for ethicists. This is shown by the fact that, even though it is usually not justified or argued for, frequent reference is made to MP in the scholarly discussion of the ethical foundations of business activity. Thus, for instance, Spinello, while discussing the ethical pricing of pharmaceutical drugs, makes the point that "mutual benefit is the essence of a sound business relationship" (1992:624); Holley's theory of the duties of salespeople is based on his concept of a mutually beneficial market exchange (1998:638-639); Arrow (1973:309), in discussing the institutional underpinnings of the economic system, makes reference to the principles of ethics and morality, saying that "these principles are agreements, conscious, or, in many cases, unconscious, to supply mutual benefits"; and Miles and his colleagues refer to "the marketing concept premise that proper marketing relationships are mutually beneficial and create value for both the consumer and the marketer" (Miles, Munilla \& Covin, 2002:290). Other references to the idea of mutual benefit in exchanges can be found in Ebejer and Morden (1988:339), Kotler (2002:290), Nash (1990:91-94), and Santos and Laczniak (2009:11).

But even though we meet in the literature many more or less vague references to mutuality as an ethical desideratum in the relations between a firm and its customers, the authors who refer to it for the most part do not articulate that idea nor apply it consistently. Thus, for instance, Spinello (1992) argues that concern for distributive justice should be a critical factor in the equation of variables used to set prices for pharmaceuticals. He then moves on to conclude that the whole burden of making essential treatments available to those who need them but cannot afford them should fall on the pharmaceutical companies that produce them, rather than being spread, through the social security and tax systems, among all the members of a given society. I cannot address this most complex issue here, but it seems clear that this view goes so far beyond the requirements of a principle of mutuality in commercial dealings as to negate it. Holley defends a mutual benefit rule in trying to render more precise the obligation of salespeople to disclose information to their customers. However, his main concern is to advance "the ends the marketplace is expected to serve" (1998:634), rather than to protect justice in each individual exchange, and his understanding of the requirements of mutuality is significantly different from the one I advance in this paper. Arrow (1973) and Miles (1993) only make passing references to the idea of mutuality. 
It seems clear, therefore, that if MP is going to be more than a rhetorical flourish, much work needs to be done in defining and defending it. An important point of departure for this work is that there is very wide support in the ethics literature for the idea that in our relations with others we should go beyond mere egoism, even if this egoism is tempered by observance of the law. Perhaps the formulation of this idea that is most general and garners the widest acceptance is that of a principle of beneficence, which in Beauchamp's words can be described as "a moral obligation to act for the others' benefit, helping them to further their important and legitimate interests, often by preventing or removing possible harms" (Beauchamp, 2013).

The opposite of following the principle of beneficence is an attitude of systematic egoism. Approaching commercial transactions with an attitude of extracting as much value as possible from them, while being unconcerned with the benefits accruing from them to one's transactors, only makes sense for people who have adopted, or are ready to adopt, egoism as a general attitude in all spheres of their lives. For most ethicists, and for most ordinary people, this is too high a price to pay. Although in practice all of us often behave in a selfish manner, very few people consider egoism as an ideal according to which they wish to shape their lives.

The principle of beneficence is accepted by many different schools of ethics, and for my purposes in this article, this is a great advantage, as it means that in order to accept MP it is not necessary to accept fully the teachings of any given ethical tradition, which, as I have already mentioned before, is something that very few ethicists, and even fewer professional managers, do. From a broadly Aristotelian perspective - and this is my own way of approaching this issue, which I will elaborate briefly below - the principle of beneficence is justified by its linkage to a conception of human flourishing in friendship and harmonious communities, which are seen as being intrinsically, and not just instrumentally, valuable; and to an overall conception of life according to which one's own fulfilment is not advanced, but rather made impossible, by restricting one's attention to one's narrow interests (e.g. Grisez \& Shaw, 1988:63-64; Solomon, 1993:74-90). Kantians also accept this principle and link it to a requirement of respect for persons which demands helping them to promote their ability to act autonomously when this is possible (O'Neill, 1989:115-118; Guyer, 2000:324-327; Hill, 1992). A beneficent intent towards others is also required by the personalist principle (Melé, 2009a:231-33), and even many broadly consequentialist authors argue that, in most practical circumstances, attempting to actively advance the interests of others is the policy most likely to result in promoting the general good (Kagan, 1989:9-10).

I will now sketch briefly an Aristotelian justification of the principle of beneficence. As I mentioned above, an important component of this justification is that acting in a beneficent way opens the way to participation in relationships of friendship and community. By entering into a transaction for mutual benefit, one in which the parties make a point of taking respectfully into account the other's the real interests (rather than imagined interests) and of structuring the transaction in a way that facilitates the satisfaction of their respective interests, buyer and seller engage in an activity through which "people who are not intimate cease to be strangers" (Markovits, 2004:1463); 
establish a form of limited but real community; and enter into a harmonious relationship which has value in itself beyond the concrete benefits each of the parties may get from the transaction (Fried, 1981:8; Grisez \& Boyle, 1979:457-458). On the other hand, a party who does not exchange on fair terms thereby refuses an opportunity of establishing community and prefers to use the other party as a mere tool for her own ends. The element of harmonious relations with others that is inherent in fair exchanges is most clear in the case of long-term relationships in which both parties seek reciprocity. But even in the case of an isolated transaction in which only one of the parties is mindful of the interest of the other, that party still defines herself through her (unreciprocated) choice in that isolated transaction as somebody who values just community and harmonious relations, and that in itself is already a good way to be. As Grisez and Boyle (1979:458) say, "[I]iving justly together is not merely a means to some other good; it is an important aspect of the self-fulfilment as human persons of all those who are dedicated to it".

We can go more deeply into these issues by trying to examine further the relationship between friendship and community on the one hand, and flourishing on the other. ${ }^{3}$ The work of Aristotle provides a useful point of departure for considering this issue. For Aristotle, friendship is an important aspect of human flourishing, and he says things such as: "a good friend is by nature desirable for a good man"; "[friendship] is necessary for living"; "the happy man needs friends"; "[n]obody would choose to live without friends, even if he had all the other good things"; and "friends are considered to be the greatest of external goods" (Aristotle, 1976:VIII, i and IX, ix).

A possible difficulty in approaching a relationship of mutuality with one's customer as a form of friendship is that Aristotle himself, near the beginning of his treatment of friendship (1976:VIII, iii), distinguishes three varieties or species of friendship: friendship of goodness, friendship of pleasure and friendship of utility, and explicitly states that only the first class is "true friendship" (VIII, vi), perfect of its kind, while the last two are "secondary forms of friendship" (VIII, vi), "grounded on an inessential factor" (VIII, iii); and "of a less genuine kind" (VIII, iv), and can easily be dissolved (VIII, iii). Should we conclude from this that a relationship with one's customer can at best become one of these inferior types of friendship and that, though perhaps it may be useful for some purposes, it cannot possibly be an aspect of true human flourishing? This conclusion would not seem sound, as in his discussion of friendship Aristotle makes reference to many other types of friendship that, while not being instances of the focal case of friendship between two mature good men, are also not instances of any of the two secondary forms of friendship (pleasure and utility) which he specifically identifies. Examples are the "mutual friendliness between members [...] of the human species" (VIII, i); friendship among the members of a community (VIII, i and ix) or the citizens of a state (IX, vi); friendship between parents and their children (VIII, i), brothers (VIII, ix) and husband and wife (VIII, vii); and friendship among those serving on the same ship or in the same force (VIII, ix), or among members of the same social club (VIII, xi). All these cases of friendship can be best thought of as derivative instances of the concept (because, in Aristotle's view, they do not instantiate to the full all the traits of the central case), but which are still good and valuable as they exhibit some of these traits. 
Probably a better way of thinking of the wide variety of cases that share a certain 'family resemblance' with the central case of friendship but fail to exhibit to the full its valuable traits, yet do not have any traits that are negative in themselves, is to consider friendship, as Finnis (2011a and 2011b) does, within the wider matrix of 'harmony'. Finnis considers several types of harmonious relations, including harmony within oneself ("between one's feelings and one's judgments [inner integrity], and between one's judgments and one's behaviour [authenticity]); "harmony between persons in its various forms and strengths; and "harmony with the widest reaches and most ultimate source of all reality, including meaning and value" (2011a:244 n). There are many types of harmony between persons, ranging, in the number of people they include, from the love between two lovers to the possible harmony among all human beings, through - to refer only to instances to which Finnis refers in his writings - harmony among fellow citizens, neighbours, family members and people sharing the same workplace or the same city. Finnis himself refers most generally to "the range of forms of human community/society/friendship" (1980:135) and explicitly makes this whole range the subject matter of his own study.

I hope that these summary comments go some way towards clarifying both how the relationship between buyer and seller can display this type of valuable harmony, and how that harmony is indeed a form of friendship, whose intrinsic value, as illuminated by the consideration of more focal cases of friendship, derives from the fact that the two parties share common goals and are committed, in a limited but real way, to the wellbeing of each other, though perhaps without the intensity and even exclusivity that is typical of the central cases of friendship.

It is interesting to observe that there is a long tradition of ethical reflection that specifically translates the general requirement of benevolence into a more specific requirement of equality in exchanges. Aristotle stated that 'equality', or equivalence, is the main requirement that has to be met for an exchange to be fair (1976:181). Scholastic authors accepted the basic idea that what many of them called commutative justice, that is to say, justice in dealings among private parties, is based on there being (or on restoring) equality between what is given and received in a transaction. Preeminent among them, Aquinas stated explicitly that "all contracts should observe equality between the parties in respect of their subject matter" (2006, II-II, 77 a. 1c). More than three centuries after Aquinas, we find the same idea reaffirmed by the members of the Salamanca School. To take only one example from this school, Tomás de Mercado said that "dealing in a just manner is to ensure equality and equity in contracts" (1975:112). ${ }^{4}$

It seems clear that in both Aristotle and Aquinas the requirement of equality is linked to a broader requirement of benevolence towards others. Without going farther afield, it may suffice to mention here that Aristotle includes in the middle of his account of 'corrective justice' (justice which rectifies inequalities that arise in dealings between individuals) a reference to how a temple to the Graces was set up in a public place to encourage the repayment of benefits, "because it is right both to repay a service to a benefactor and at another time to take the initiative in benefaction" (Aristotle 1976:V, 5). Similarly, just before Aquinas states that all contracts should observe equality, he says: 
"Buying and selling seem to be established for the common advantage of both parties [...] Now whatever is established for the common advantage should not be more of a burden to one party than to another" (2006:II-II, 77, 1). These references to mutual benefits are premised on a conception of social life, and specifically of trading, as a cooperative undertaking. While neither Aquinas' nor Aristotle's arguments on this point are fully developed, from what they say the basic idea which seems to justify the requirement of equality between what parties give and what they receive is that people who violate this requirement do not behave like participants in a cooperative enterprise, but rather like people unconcerned with their responsibilities to others and out to get for themselves as much as they can.

Some may object to the preceding line of argument by arguing that it may be applicable to the exchanges of individual human beings, but that business organisations are not the type of entities to which these arguments can apply. As Duska has stated, "[a] company is not a person. A company is an instrument, and an instrument with a specific purpose, the making of profit. To treat an instrument as an end in itself [...] does give the instrument a moral status it does not deserve" (Duska, 1997:338). But this objection does not seem fatal to me. In the first place, even if the basis of the objection were accepted, it would still be possible to reply that, as Markovits (2004:1465) has observed,

[exchange $]^{5}$ involving organizations might engender collaboration among the individual persons who, as stakeholders in the organizations, stand behind the organizations and bear the consequences of their contractual activity; and second, [exchanges] involving organizations might engender collaboration among the individual persons who, as the organizations' agents, front the organizations and contract on their behalves.

More radically, however, we should object to the characterisation of a business firm as a mere instrument. For the limited purpose of this argument, it is not necessary to offer a full definition of business firms and their purposes. Whatever these purposes might be, the most superficial examination of a business firm shows it to be a group of human beings acting in concert to a certain extent, and it is always possible (however difficult it may be) to seek to establish community with a group of human beings through entering into fair exchanges with them as they act as a group.

From an Aristotelian perspective, another important link between the principle of beneficence and human flourishing is provided by the concept of 'intelligent action'. For Aristotle, the highest human good or eudaimonia is attained through the exercise of our intelligence in contemplation and in action (1976:I, vii)). How this can be related to the relationship of a seller with her buyers is most succinctly expressed by John Finnis (2011b:420): "[...] to violate the Golden Rule is to allow emotional motivations for selfinterested preference - independent of rational grounds for prioritizing among persons - to override the rational rule of fair impartiality." In other words, by failing to practice fairness in her relations with her customers, the seller fails to allow her conduct to be governed by reason, and so fails to practice intelligent action. 


\section{Why not go beyond mutuality?}

The arguments in the preceding subsection show why it is a requirement of justice for the seller to provide to her buyers economic value which is at least commensurate with the price they pay. But at this point, it could be asked whether it would not be even more ethical for the seller to do even better for her buyers by charging them a lower price, increasing the quality of the product, or providing better after-sales service. The answer to this is that if a seller manages to create significant value, for instance by coming up with a cheap way to make a very valuable product, and leaving aside here cases in which a buyer finds himself in a situation of grave need, there are no cogent reasons to argue that she should be under a duty to provide an even better value, or the same value at a lower price, until she reaches the limit of covering her costs and making only a moderate profit.

Think, for instance, of somebody who through her innovative efforts has succeeded in creating a product that delivers to her buyers higher value than competing products, but which costs significantly less to manufacture than those competing products, and therefore can be very profitable for the seller if it is sold at a similar price as that of competing products. It is possible, however, by incurring additional costs, to increase even further the quality of the product and the value it delivers to customers. The issue now is whether the seller has a duty to increase as much as possible the quality of her product in order to give her customers the best possible deal she can. It is highly relevant to this question to keep in mind that if the product delivers to buyers higher value than competing products, and it is sold at a similar price, there will be already a large element of gift implicit in each sale. By increasing the quality (and incurring additional costs) that element of gift would be increased even further. However, no mainstream theory of justice - Aristotelian, utilitarian, Kantian, Thomist or personalist - requires moral agents to provide the largest possible gifts they can afford to all individuals with whom they interact, provided they do not stand in a special relationship to those individuals and the latter are not in a position of special need. It is also relevant that, in the example we are considering, by increasing her costs in order to provide even greater quality, the innovator will reach the point at which she only captures enough value to secure for herself a moderate profit, and thus will not be able to come to the help of other people towards whom she has more pressing obligations, either by reason of her special relationship to them or of their special situation of need.

Even if we allow that it would be permissible in such circumstances for the seller not to increase its quality as much as it is feasible, we can still enquire whether it would be even more ethically praiseworthy for her to move beyond mutuality to beneficence; beyond reciprocity to free-giving. However, there are many reasons why this course of action, which indeed could be appropriate in some cases, cannot be generally recommended.

A general standard, suggesting to freely give away as much as possible to one's counterparties in commercial transactions seems to assume that free-giving is the ideal principle of behaviour. But free-giving is not the only, and in the great majority of cases not even the best, way of showing concern for the well-being of others. Generally speaking, cooperation for mutual advantage will be a more appropriate principle of interaction 
between competent, self-sufficient people, who are the typical actors in modern, developed, market-oriented economies. Also, as I indicated above, a blanket requirement of free-giving as a general principle of justice in business exchanges would leave no room for recognising a reasonable order of priorities in our responsibilities. People who do as well as possible for their counterparties in exchanges will be doing very well for many strangers, but very likely will fail to obtain enough benefits for themselves to be able to take care of some of the special needs of people (such as their employees, their investors, their relatives, and the members of their communities) towards whom they bear a greater and more immediate responsibility. Business people have a responsibility to support their families and dependents and to ensure that their employees and investors receive appropriate returns from their participation in the business, and such responsibilities will usually place stringent limits on what it will be appropriate to do by way of freegiving for one's business customers.

Another important consideration that in many cases will militate against a general principle of giving the best possible deal to the other party is that, in most commercial transactions, the specific counterparties with whom we deal are not especially needy people. It is not clear, to say the least, why a seller should be under a general obligation to give the best possible deal to her customers when many of them may be wealthier than she is and do not need any special help from her.

Of course, in certain circumstances giving as much value for money as possible might be the ethical course of action, and in some circumstances it may even be ethically required, but if the points made in the preceding paragraphs are cogent, this is not something that can be demanded generally. The main point I have tried to establish in this article is that the fundamental requirement of justice is simply to give equivalent value for money, not necessarily to give the best possible deal.

The reason why the arguments in the preceding paragraphs are very general is that it is only in this form that they can be compatible with different ethical frameworks, an objective that I have tried to attain throughout this article. Once a specific set of ultimate ethical principles is adopted, it should be possible in many cases to give a more definite form to the outline presented here.

A brief recap of the line of argument up to this point may be useful here. I have argued in favour of a principle of mutuality (MP) to guide decisions in the field of marketing ethics. MP encapsulates an idea of reciprocity in the relations between seller and buyer. It does not demand an all-out effort on the part of the seller to give to the buyer the best possible service and the lowest possible price to the point of neglecting her own interests, but it does demand a sincere effort to advance the interests of the buyer in the exchange transaction and that the seller's benefits from the transaction be a just (commensurate) reward for the benefits it has provided to the buyer. The basic justification for MP is that it reflects a more basic attitude of non-exploitative cooperation on the part of the seller, which still allows her to advance her own interests. 
I have argued that MP is superior to the principles of consumer sovereignty and preserving the conditions of an acceptable exchange, because the latter principles depend on a desire-fulfilment theory of well-being that cannot withstand critical scrutiny and place unrealistic burdens on sellers. I also contend that MP is superior to a principle of paternalism, because the latter neglects the fact that self-determination is itself a great human good. Finally, I have argued for the superiority of MP over the perfect competition ideal, on the basis that the latter moves illegitimately from the advantages that would ensue for all in a model world in which that ideal obtained, to a prescription for action in the real world, which is often far removed from that model.

In order to round up the discussion of MP, I will now proceed to discuss further the implications of its being a mid-level principle rather than an ultimate ethical principle or a specific ethical norm.

\section{A comparison of the mutuality principle with other ethical principles relevant to the field of marketing ethics}

The role of a 'mid-level' ethical principle such as MP can be better understood if it is contrasted with other ethical principles which have been deployed in the marketing ethics literature. Note that the principles I will refer to in this section are different from those principles I have already examined above, such as consumer sovereignty and paternalism. These previously discussed principles are direct competitors of MP for the role of mid-level unifying ethical principle for the field of marketing, as: (i) they are not ultimate ethical principles, but try to capture the main implications of ultimate principles for the field of marketing; (ii) they are wide enough in scope to provide guidance in many of the ethical issues that arise in marketing and justify many more immediately applicable ethical norms for the field; and (iii) they can be justified from a variety of more fundamental ethical perspectives.

In contrast, the principles I will examine in this section, while they are useful and relevant when addressing issues of marketing ethics, are either applicable to a broad range of questions that goes far beyond marketing ethics, or are irrelevant to broad areas of the marketing field. I hope that these very abstract statements will become clearer as I discuss specific principles of this second type.

Many of the main ethical principles that can be applied in the marketing field are discussed in an excellent paper by Laczniak and Murphy (2006a). These writers present a set of seven "basic perspectives" which "address the broader moral dimensions that should ideally characterize the marketing and society interface" (p. 156). These "basic perspectives" are described as "a normative set of recommendations for elevating the practice of marketing ethics" (p.54, article abstract). The fact that the authors list seven such perspectives (and list five precepts within one of them) already marks an essential difference with the type of mid-level principle I put forward in this paper. The aim of my effort is to propose a single unifying mid-level principle for the field which will capture the normative implications of the type of principles that Laczniak and Murphy identify. 
I will now undertake a more detailed - though necessarily short - comparison of MP with the basic perspectives listed by Laczniak and Murphy in order to better illustrate my point.

The seven basic perspectives identified by Laczniak and Murphy (2006a) are: ${ }^{6}$ BP1 "Put People First"; BP2 - "Ethical Expectations for Marketing Must Exceed Legal Requirements"; BP3 - "Marketers Are Responsible for their Intent, as well as the Means and End of their Marketing Actions"; BP4 - "Marketing Organizations Should Cultivate Better Moral Imagination in their Managers and Employees"; BP5 - "Marketers Should Embrace a Core Set of [Five] Ethical Principles"; BP6 - "Marketers Should Adopt a Stakeholder Orientation"; and BP7 - "Marketing Organizations Ought to Delineate an Ethical Decision Making Protocol".

How do these basic perspectives relate to MP? BP1, BP2, BP3 and BP6 are more ultimate ethical principles than MP. The latter depends on (at least some of) them for its justification. BP5 is a composite of five ethical precepts that for the most part are consequences of MP. Once the latter is accepted, it provides strong support for them and makes it easier to accept them. Many people can see that these precepts have force precisely because violating them undercuts mutuality. Finally, BP4 and BP7 are more closely related to process matters - that is, they specify conditions and procedures that make it more likely for decision makers to reach sound moral conclusions - than to substantive moral issues.

Let me now attend in more detail to some of Laczniak and Murphy's basic perspectives, and specifically to those which can help us to better understand MP. As understood by Laczniak and Murphy (2006b), BP1 - "Put People First" - is complex. They state that BP1 "strongly suggests that persons (especially the consumers in a marketing transaction) should never be viewed as merely a means to a profitable end" (p. 159). As the authors state, this is a marketing-oriented version of Kant's second formulation of the categorical imperative. This is a bedrock ultimate ethical principle, and I have argued above that followers of Kantian ethics will use it to justify MP. Within this perspective, MP derives from the categorical imperative, rather than the other way around, and this is why I say that MP is a mid-level principle, while the categorical imperative is a more ultimate (in the view of Kantians, the ultimate) ethical principle. Therefore, it should be clear that MP is not offered as an alternative to other better known and more traditional ethical principles, but rather as a way of capturing, summarising and making more immediately operational the normative implications of these other ethical principles for the field of marketing ethics.

Laczniak and Murphy also state that BP1 requires as well that "the marketing decisions made by managers [seeking to provide satisfaction to a particular segment of customers] do not disadvantage society" (2006b:158; see also Santos and Laczniak, 2009), and that is why I said that BP1 is complex. This second aspect of BP1 reveals a limitation of MP. As I pointed out in introducing it, MP reflects the normative requirements of what is called commutative or restorative justice, that is to say fairness in relations between two parties. Wider issues relating to the overall welfare of society are not captured by it. 
BP5, as I indicated above, is a composite of five different ethical precepts or norms. The fifth of them - the principle of stewardship, which reminds marketing managers of their social duties to the common good (Laczniak \& Murphy, 2006b:166) - is also external to MP, which does not reflect its ethical demands.

The fourth precept contained in BP5 is the principle of distributive justice. As Laczniak and Murphy put it, "marketing practices are unethical if, over time, they contribute to the further disadvantage of those segments of the market that are least well off in terms of information, economic resources, access to supply, market literacy and other factors essential to marketplace transactions" (2006b:166, italics in the original. See also Santos and Laczniak, 2009). This is another ethical requirement that is, so to speak, external to MP. Let it be noted that this is so not because MP in any way contradicts any of these principles or norms, but simply because the scope of MP is not wide enough to capture them. In applying MP, one should be aware that it is only meant to reflect the requirements of justice in relations between the immediate parties to exchange transactions. Wider social considerations, such as the requirements of solidarity and distributive and social justice, demand to be given additional consideration in order to reach a conclusion that reflects all the demands of a sound ethics.

It emerges clearly from the points made in the preceding paragraphs that there are ethical principles, such as the categorical imperative (and others not discussed in this section but mentioned above, such as the eudaimonic principle and the Golden Rule) that are more basic and have a wider scope of application than MP. However, these more basic ultimate principles pose the problem that understanding them with the precision required to be able to apply them confidently in specific marketing situations requires significant philosophical training. This point also emerges clearly in Laczniak and Murphy (2006a). Thus, for instance, when discussing how to apply BP3 - "Marketers Are Responsible for their Intent, as well as the Means and End of their Marketing Actions"they recommend the use of Garrett's (1966) proportionality framework, but recognise the difficulty of applying it:

In the last analysis, Garrett's (1966) proportionality framework is still highly judgmental. For example, what constitutes a major negative outcome versus a minor negative outcome from an ethical standpoint? Which side effects are intended versus unintended? This entire approach rests on marketing decision makers being fairly sophisticated and reflective in their ethical perceptions and moral intuitions.

(Laczniak \& Murphy, 2006a:162; italics in the original)

Laczniak and Murphy (2006a) similarly stress the difficulty of applying some of the principles they identify when discussing BP4 - "Marketing Organizations Should cultivate Better Moral Imagination in their Managers and Employees" (p. 164) - and BP6 - "Marketers Should Adopt a Stakeholder Orientation" (p. 168). I do not point out these difficulties in order to argue for a rejection of the ethical principles recommended by Laczniak and Murphy. These are just difficulties inherent to the enterprise of trying to carry out a discriminating and accurate ethical analysis. My purpose is to stress that such more fundamental ethical principles are not easily applied by a practitioner. By comparison, MP, which incorporates the main implications of these more basic principles, 
is more easily understood and applied, even by people without specialised training in philosophy. In other words, MP is not a competitor but a complement of more basic ethical principles.

Other precepts or norms that Laczniak and Murphy (2006a:165) present as part of BP5 are: the principle of non-malfeasance -"marketers should knowingly do no major harm when discharging their marketing duties" (italics in the original); the principle of non-deception - "marketers ought to never intentionally mislead or unfairly manipulate consumers" (italics in the original); and the principle of protecting vulnerable market segments - "marketers should always take extraordinary care when engaging in exchanges with vulnerable segments" (italics in the original). These three norms are best presented - at least within the field of marketing ethics - as consequences or concretisations of the more general MP. Once one has seen the rationale for endeavouring to attain mutuality in exchanges, it follows that harming or deceiving customers is excluded, and also that special care should be taken when dealing with more vulnerable customers, as they are less able to look after their own interests.

Thus, the best way of thinking of the relation of MP to the ethical principles discussed by Laczniak and Murphy is to conceive of the overall process of ethical reasoning as running from the most fundamental ethical principles (as for instance the categorical imperative for Kantians) to a mid-level principle applicable to a limited domain of human activities (such as MP for marketing activities), and from there to more specific moral norms such as the duties to provide safe products (non-malfeasance) and not to intentionally mislead customers.

\section{Conclusion}

In this article I have discussed and criticised the main mid-level ethical principles that have been proposed by business ethicists to unify, clarify and articulate the ethical responsibilities of marketers. As I have concluded that none of these putative mid-level principles of marketing ethics is fully satisfactory, I have put forward MP as a more appropriate mid-level ethical principle to regulate the responsibilities of sellers towards their buyers. This principle requires that sellers avoid seeking unilateral advantage in their dealings with buyers and that they seek instead that there be real reciprocity in the relationship. In accordance with this principle, the main responsibility of a firm towards its customers is that of providing them with goods and services that are effectively capable of contributing to their well-being and personal advancement, within the framework of a mutually beneficial exchange in which there is equivalence between the benefits given and received by the parties.

I also have examined the main arguments that can be offered in support of this principle and ultimately have traced it back to a cooperative conception of social and business life that, while demanding that we do not regard our business transactors merely as a means to make a profit, does not require that we forget our own interests and those of our associates and dependents in advancing the transactors' interests. 
By identifying MP as a sound mid-level principle from which the duties of transactors in market exchanges can be derived, this article makes two main contributions. In the first place, it makes it easier for business ethicists of different ethical schools to cooperate in the field of marketing ethics without having to compromise their more ultimate principles. In so far as their more basic ethical principles support MP - and we have seen how the ultimate principles of several important ethical schools do so - it will be possible for them to cooperate in identifying and refining concrete ethical norms for the field of marketing, for instance in drafting an ethical code for a professional association or a business firm. Secondly, MP makes it easier for practitioners to reason ethically in the concrete situations they face in their professional activity. It is very difficult for a medical doctor to identify all the fundamental ethical principles that may have a bearing on a treatment decision she has to make and to decide on their priority and bearing on that case, but is relatively easy to apply the principle of informed consent. Similarly, it is much easier to apply MP to a decision on pricing than to try to reach that decision on the basis of ultimate ethical principles. Business ethicists have already done work in trying to identify a mid-level unifying principle for the field of marketing, but I have argued in this paper that the main candidates they have suggested for this role are vulnerable to damaging criticisms and that MP is superior to them.

In acknowledging the limitations of this article, it is important to note that I do not claim that MP exhausts all our duties - not even all our duties of justice - towards other individuals and towards our communities. The duties specified by MP are the duties of transactors in exchanges among self-sufficient parties (that is, parties who are not unable to satisfy their basic needs). What the duties are that each of us has in relation to transactors who are not self-sufficient, other parties and our communities is simply not the subject matter of this article.

\section{References}

Anderson, E. 1995. Value in ethics and economics. Cambridge, MA: Harvard University Press.

Aquinas, T. 2006. Summa theologiae. In: English Province of the Order of Preachers (eds.). Cambridge, UK: Cambridge University Press.

Aristotle. 1976. The ethics of Aristotle. The Nicomachean ethics. Translated by J.A.K. Thomson. London: Penguin Classics.

Arneson, R.J. 1999. Human flourishing versus desire satisfaction. Social Philosophy and Policy, 16(1):113-412. DOI: $10.1017 / \mathrm{S} 0265052500002272$

Arneson, R.J. 2005. Joel Feinberg and the justification of hard paternalism. Legal Theory, 11(2):59-84. DOI: 10.1017/s1352325205050147

Arrow, K. 1973. Social responsibility and economic efficiency. Public Policy, 21:303-317.

Baker, S.M., Gentry, J.W. \& Rittenburg, T.L. 2005. Building understanding of the domain of consumer vulnerability. Journal of Macromarketing, 25(2):1-12. DOI: 10.1177/0276146705280622

Beauchamp, T. 2013. The principle of beneficence in applied ethics. In: E.N. Zalta (ed.). The Stanford Encyclopaedia of Philosophy. Winter 2013 Edition. http://plato.stanford.edu/archives/win2013/entries/ principle-beneficence/ [Accessed: 10 June 2015].

Berlin, I. 1969. Four essays on liberty. Oxford: Oxford University Press. 
Bhandari, B.S. 1997. Some ethical issues in computation and disclosure of interest rate and cost of credit. Journal of Business Ethics, 16:531-535. DOI: 10.1023/A:1017993704216

Brandt, R.B. 1979. A Theory of the good and the right. Oxford: Clarendon.

Brenkert, G. 1998. Marketing to inner-city blacks: Powermaster and moral responsibility. Business Ethics Quarterly, 8(1):1-18. DOI: 10.2307/3857519

Brock, G. 1996. Paternalism and the (overly?) caring life. Business Ethics Quarterly, 6(4):533-548. DOI: $10.2307 / 3857504$

Brockway, G. 1993. Limited paternalism and the salesperson: A reconsideration. Journal of Business Ethics, 12:275-279. DOI: 10.1007/BF01666531

Broome J. 1999. Ethics out of economics. New York, NY: Cambridge University Press. DOI: 10.1017/ CBO9780511605888

Camenisch, P.F. 1991. Marketing ethics: Some dimensions of the challenge. Journal of Business Ethics, 10:245-248. DOI: 10.1007/BF00382961

Carson, T. 2001. Deception and withholding information in sales. Business Ethics Quarterly, 11(2):275-306. DOI: $10.2307 / 3857750$

Chaplin, L.N. \& Roedder, D. 2007. Growing up in a material world: Age differences in materialism in children and adolescents. Journal of Consumer Research, 34(4):480-493. DOI: 10.1086/518546

Crisp, R. 2013. Well-being. In: E.N. Zalta (ed.). The Stanford Encyclopaedia of Philosophy. http://plato. stanford.edu/archives/sum2013/entries/well-being [Accessed: 1 January 2016].

Duska, R. 1997. Whistle-blowing and employee loyalty. In: T.L. Beauchamp \& N.E. Bowie (eds.). Ethical theory and business. Upper Saddle River, NJ: Prentice Hall. 155-59.

Dworkin, G. 1988. Paternalism: The theory and practice of autonomy. Cambridge, UK: Cambridge University Press. DOI: $10.1017 /$ CBO9780511625206

Dworkin, G. 2010. “Paternalism”.In E. Zalta (Ed.), The Stanford Encyclopedia of Philosophy. http://plato. stanford.edu/archives/sum2020/entries/paternalism/

Ebejer, J.M. \& Morden, M.J. 1988. Paternalism in the marketplace: Should a salesman be his buyer's keeper? Journal of Business Ethics, 7:337-339. DOI: 10.1007/BF00382535

Elegido, J. 1998. La responsabilidad básica de la empresa hacia sus clientes. In: D. Melé (ed.). Etica en Dirección Comercial y Publicidad. Barcelona: Estudios y Ediciones IESE. 87-102. (English version http://ssrn.com/ abstract $=2464617$ [Accessed: 1 January 2016].)

Elegido, J.M. 2009. The just price:Three insights from the Salamanca School. Journal of Business Ethics, 90:29-46. DOI: 10.1007/s10551-008-0024-6

Elegido, J.M. 2013. Does it make sense to be a loyal employee? Journal of Business Ethics, 116(3):495-511. DOI: $10.1007 / \mathrm{s} 10551-012-1482-4$

Elegido, J.M. 2015. The just price as the price obtainable in an open market. Journal of Business Ethics, 130(3):557-572. DOI: 10.1007/s10551-014-2240-6

Enderle, G. \& Niu, Q. 2012. Discerning ethical challenges for marketing in China. Asian Journal of Business Ethics, 1:143-162. DOI: 10.1007/s13520-011-0014-0

Feinberg, J. 1986. The moral limits of the criminal law: Harm to self. Volume 3. New York, NY: Oxford University Press.

Finnis, J. 1980. Natural law and natural rights. Oxford: Clarendon Press.

Finnis, J. 2011a. Commensuration and public reason. In: J. Finnis. Reason in Action: Collected Essays. Volume I. Oxford: Oxford University Press. 233-255. DOI: 10.1093/acprof:oso/9780199580057.003.0016

Finnis, J. 2011b. Natural law and natural rights. 2nd Edition. New York, NY: Oxford University Press.

Freiman, C. \& Nichols, S. 2011. Is desert in the details? Philosophy and Phenomenological Research, 82(1):121-133. DOI: 10.1111/j.1933-1592.2010.00387.x

Fried, C. 1981. Contract as a promise. Cambridge, MA: Harvard University Press. 
Garrett, T. 1966. Business ethics. Englewood Cliffs, NJ: Prentice Hall.

Gaski, JF. 1999. Does marketing ethics really have anything to say? A critical inventory of the literature. Journal of Business Ethics, 18:315-334. DOI: 10.1023/A:1017190829683

Gibbs, P. 2004. Marketing and the notion of well-being. Business Ethics: A European Review, 13(1):5-13. DOI: 10.1111/j.1467-8608.2004.00344.x

Gibbs, P. 2009. Response to 'Gibbs and the problems of satisfaction and well-being.' Business Ethics: A European Review, 18(4):412-413. DOI: 10.1111/j.1467-8608.2009.01573.x

Griffin, J. 1986. Well-being: Its meaning, measurement, and moral importance. Oxford: Oxford University Press.

Grisez, G. \& Boyle, J.M. 1979. Life and death with liberty and justice: A contribution to the euthanasia debate. Notre Dame, In: University of Notre Dame Press.

Grisez, G. \& Shaw, R. 1988. Beyond the New Morality. 3rd Edition. Notre Dame, In: University of Notre Dame Press.

Grisez, G. 1978. Against consequentialism. American Journal of Jurisprudence, 23:21-72.

Grisez, G. 1997. The way of the Lord Jesus: Difficult moral questions. Volume III. Quincy, IL: Franciscan Press.

Guitián, G. 2015. Service as a bridge between ethical principles and business practice: A Catholic Social Teaching perspective. Journal of Business Ethics, 128(1):59-72.

Guyer, P. 2000. Kant on freedom, law, and happiness. Cambridge, UK: Cambridge University Press.

Hardman, D. 2009. Judgment and decision making: Psychological perspectives. Chichester: John Wiley \& Sons.

Hill, T. 1992. Dignity and Practical Reason in Kant's Moral Theory. Ithaca, NY: Cornell University Press.

Hogarth, R.M. 1987. Judgment and choice: The psychology of decision. 2nd Edition. Chichester: John Wiley \& Sons.

Holley, D.M. 1986. A moral evaluation of sales practices. Business \& Professional Ethics Journal, 5(1):3-21. DOI: 10.5840/bpej 19865120

Holley, D.M. 1998. Information disclosure in sales. Journal of Business Ethics, 17:631-641.

Holley, D.M. 2002. Alternative approaches to applied ethics: A response to Carson's critique. Business Ethics Quarterly, 12(1):73-82. DOI: 10.2307/3857649

Kagan, S. 1989. The limits of morality. Oxford: Clarendon Press.

Kotler, P. 2002. Kotler on marketing. New York, NY: The Free Press.

Kultgen, J. 1995. Autonomy and intervention: Parentalism in the caring life. New York, NY: Oxford University Press.

Laczniak, G.R. \& Murphy, P.E. 2006a. Normative perspectives for ethical and socially responsible marketing. Journal of Macromarketing, 26(2):154-177. DOI: 10.1177/0276146706290924

Laczniak, G.R. \& Murphy, P.E. 2006b. Marketing, consumers and technology: Perspectives for enhancing ethical transactions. Business Ethics Quarterly, 16(3):313-321. DOI: 10.5840/beq200616330

Lewinsohn-Zamir, D. 2003. The objectivity of well-being and the objectives of property law. New York University Law Review, 78:1669-1754.

Markovits, D. 2004. Contract and collaboration. The Yale Law Journal, 113:1417-1518. DOI: 10.2307/4135772

Melé, D. 2009a. Integrating personalism into virtue-based business ethics: The personalist and the common good principles. Journal of Business Ethics, 88(1):227-244. DOI: 10.1007/s10551-009-0108-y

Melé, D. 2009b. Business ethics in action: Seeking human excellence in organizations. Basingstoke: Palgrave Macmillan.

Mercado, T. 1975. Suma de tratos y contratos. Sierra Bravo, R. (ed.). Madrid: Editora Nacional.

Miles, G.1993. In search of ethical profits: Insights from strategic management. Journal of Business Ethics,12: 219-225. DOI: 10.1007/BF01686449

Miles, M.P., Munilla, L.S. \& Covin, J.G. 2002. The constant gardener revisited: The effect of social blackmail on the marketing concept, innovation, and entrepreneurship. Journal of Business Ethics, 41(3):287-295. DOI: 10.1023/A:1021241129501 
Mill, J.S. 1956. On liberty. Indianapolis, In: Bobbs-Merrill.

Mochrie, R.I. 2006. Justice in exchange: The economic philosophy of John Duns Scotus. Journal of Markets \& Morality, 9(1):35-56.

Nash, L. 1990. Good intentions aside: A manager's guide to resolving ethical problems. Cambridge, MA: Harvard Business School Press.

Nill, A. \& Schibrowsky, J.A. 2007. Research on marketing ethics: A systematic review of the literature. Journal of Macromarketing, 27(3):256-273. DOI: 10.1177/0276146707304733

O’Neill, O. 1989. Constructions of Reason. Cambridge, UK: Cambridge University Press.

Parfit, D. 1984. Reasons and persons. Oxford: Oxford University Press.

Pellegrino E.D. \& Thomasma, D.C. 1993. The virtues in medical practice. New York, NY: Oxford University Press.

Penz, G.P. 1986. Consumer sovereignty and human interests. Cambridge, UK: Cambridge University Press. DOI: $10.1017 / C B O 9780511895944$

Primaux, P. \& Stieber, J. 1999. When MR = MC: Ethical efficiencies in value and pricing. Journal of Business Ethics, 18(2):201-211. DOI: 10.1023/A:1005794907672

Santos, N.J.C. \& Laczniak, G.R. 2009. Marketing to the poor: An integrative justice model for engaging impoverished market segments. Journal of Public Policy \& Marketing, 28(1):3-15. DOI: 10.1509/jppm.28.1.3

Scanlon, T.M. 1975. Preference and urgency. The Journal of Philosophy, 72:655-669. DOI: 10.2307/2024630

Schlegelmilch, B. \& Oberseder, M. 2010. Half a century of marketing ethics: Shifting perspectives and emerging trends. Journal of Business Ethics, 93(1):1-19. DOI: 10.1007/s10551-009-0182-1

Schor, J. 2004. Born to buy: The commercial culture and the new consumer culture. New York, NY: Scribner.

Sen, A.K. 1985. Well-being, agency and freedom: The Dewey Lectures 1984. The Journal of Philosophy, 82:169-221. DOI: 10.5840/jphil198582466

Sirgy, J.M. 1996. Strategic marketing planning guided by the Quality-of-Life (QOL) concept. Journal of Business Ethics, 15(3):241-259. DOI: 10.1007/BF00382951

Sirgy, J.M. \& Su, G. 2000. The ethics of consumer sovereignty in an age of high tech. Journal of Business Ethics, 28(1):1-14. DOI: 10.1023/A:1006285701103

Sirgy, J.M., Lee, D. \& Grace, B.Y. 2011. Consumer sovereignty in healthcare: Fact or fiction? Journal of Business Ethics, 101(3):459-474.

Smith, C.N. 1995. Marketing strategies for the ethics era. Sloan Management Review, 36:85-97.

Smith, C.N. \& Cooper-Martin, E. 1997. Ethics and target marketing: The role of product harm and consumer vulnerability. The Journal of Marketing, 61(3)1-20. DOI: 10.2307/1251786

Solomon, R.C. 1993. Ethics and Excellence. Oxford: Oxford University Press.

Spinello, R.A. 1992. Ethics, pricing and the pharmaceutical industry. Journal of Business Ethics, 11:617-626. DOI: $10.1007 / B F 00872273$

Strutton D., Hamilton, J.B. \& Lumpkin, J.R. 1997. An essay on when to fully disclose in sales relationships: Applying two practical guidelines for addressing truth-telling problems. Journal of Business Ethics, 16(5:545-560.

Velasquez, M.G. 2006. Business ethics: Concepts and cases. 6th Edition. Upper Saddle River, NJ: Pearson.

Walters, K.S. 1989. Limited paternalism and the Pontius Pilate plight. Journal of Business Ethics, 8(12):955-962. DOI: $10.1007 /$ BF00383432

Wertheimer, A. 1996. Exploitation. Princeton, NJ: Princeton University Press.

Whysall, P. 2000. Marketing ethics - An overview. The Marketing Review, 1(2):175-195. DOI: $10.1362 / 1469347002529152$

Zamir, E. 1997. The inverted hierarchy of contract interpretation and supplementation. Columbia Law Review, 97:1710-1803. DOI: $10.2307 / 1123389$ 


\section{Endnotes}

1 I do not discuss in this article Ebejer and Morden (1988), even though it is an excellent paper and I substantially agree with the thesis for which it argues. The reason is that it is a very short paper which restricts itself to a consideration of sales situations, while I am interested in the full arch of the relationship seller-buyer. The thesis of that article was further discussed in Walters (1989) and Brockway (1993).

2 On this requirement, Holley is significantly more restrained, and would not be vulnerable to the criticisms I address to Smith.

3 In this and the following paragraphs I have made use of previous work in Elegido (2013).

4 All these authors speak of 'equality'. As I acknowledge them as my predecessors, the question may arise whether it would not be better for me to speak of a principle of equality in exchanges, rather than a principle of mutuality. I do not think that much turns on the term chosen; still, I prefer 'mutuality' for several reasons. In the first place, as I indicated above, the term 'mutuality' keeps cropping up in current discussions of the issues that interest me here, and there is much to be said for not straying too far from what seems to resonate with other scholars. More importantly, most of the authors I have referred to speak of equality in relation to what the parties give and receive, most often a price for a product. However, as I indicated above, in this paper I am trying to identify a principle capable of guiding not only pricing decisions, but, more generally, marketing activities, such as product design, advertising, promotion, distribution and personal selling. For this purpose, the term 'mutuality', with its undertones of reciprocity and cooperation, has the great advantage that it can be applied to a wider range of issues than 'equality'. As I will show below, Aristotle and Aquinas, also link the principle of equality to more general standards which are closer to the idea of mutuality, such as reciprocity, cooperation and the Golden Rule. To conclude, while I have no problem with a principle of equality in exchanges, and have actually deployed it in relation to the issue of justice in pricing (Elegido, 1998 and 2015), I think it better to speak of mutuality when trying to cover the wider arc of the responsibilities of a marketer towards her consumers.

5 Markovits speaks of contracts, rather than exchanges.

6 In formulating their principles I have combined the titles which Laczniak and Murphy (2006a) use as section headings, some of the statements within the body of their article, and the summary statements in their Figure 2. 